\title{
IMÁGENES VIVAS SOBRE FOTOS FIJAS Fotograma: Encuentro Internacional de Fotografía 2009
}

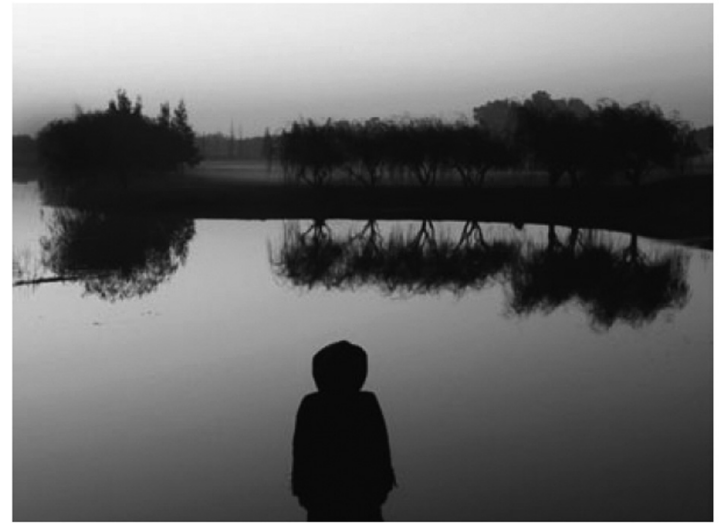

Fotografía de la colección Aguas turbulentas, donde se entremezclan el poder de la naturaleza y la fuerza del hombre. Autor: Sergio Tantanian.

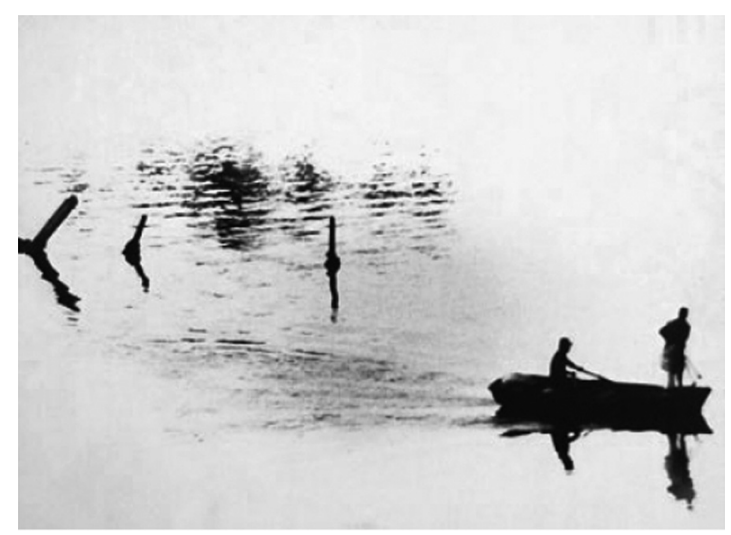

Fotografia de la colección Entre palos y botes, donde el autor utiliza el alto contraste para mostrar los detalles más significativos de cada toma. Autor: Fabrizio Vignali.

Desde el primer dia de octubre y hasta el 22 de diciembre, tuvo lugar en nuestro país la segunda edición de Fotograma, el Encuentro Internacional de Fotografía que organiza cada dos años el Centro Municipal de Fotografía (CMDF) de la Intendencia Municipal de Montevideo (IMM).

Este año Uruguay fue el escenario de más de 150 muestras fotográficas de 500 expositores nacionales y del mundo, que se pusieron en diálogo con un público tan variado como los temas del Encuentro. Con el objetivo de generar una plataforma de intercambio y formación que exponga el panorama de la producción fotográfica de Uruguay y del exterior, se organizaron muestras de fotografía, charlas, talleres y otras actividades en todos los departamentos del país, con propuestas de paises como Alemania, Argentina, Brasil, Corea, Estados Unidos, Francia, Inglaterra, Irlanda, México, Nigeria, Paraguay, Perú, Suiza y Suecia.

La Universidad Católica del Uruguay también fue uno de los escenarios de Fotograma, con la exposición del argentino Walter Astrada, "La violencia contra las mujeres, la violación de derechos humanos más extendida y menos condenada". Esta exposición estará abierta hasta finales de febrero de 2010.

Más información: http://fotograma.montevideo.gub.uy

Fotos cedidas por la organización de Fotograma 


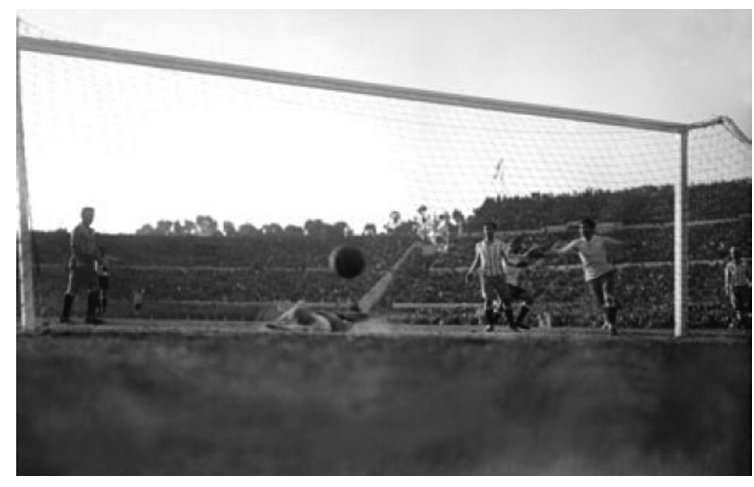

Estadio Centenario. Final del Campeonato Mundial de Fútbol (1930). Esta fotografia pertenece al Grupo de Series Históricas del Centro Municipal de Fotografía (CMDF), integrado por el trabajo realizado por fotógrafos municipales desde 1916 hasta 1990. Foto cedida por CMDF.

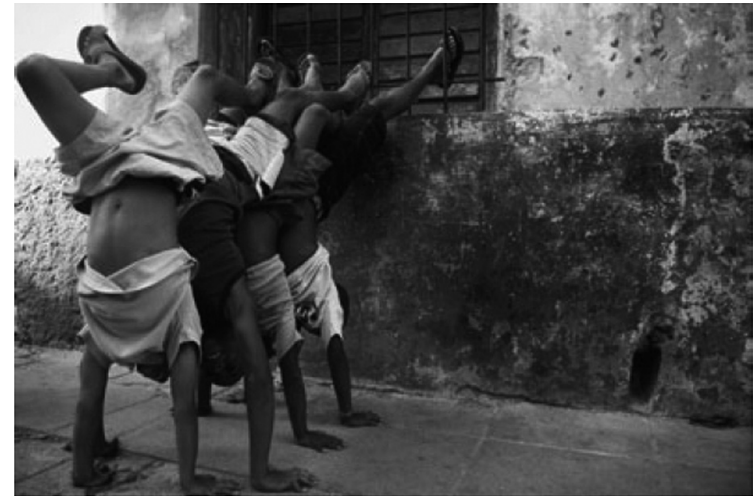

Fotografía de la colección Desde Cuba: imágenes que el tiempo no quiere borrar, que presenta un subjetivo vuelo por Cuba y constituye una importante documentación antropológica. Autor: Guillermo Giansanti.

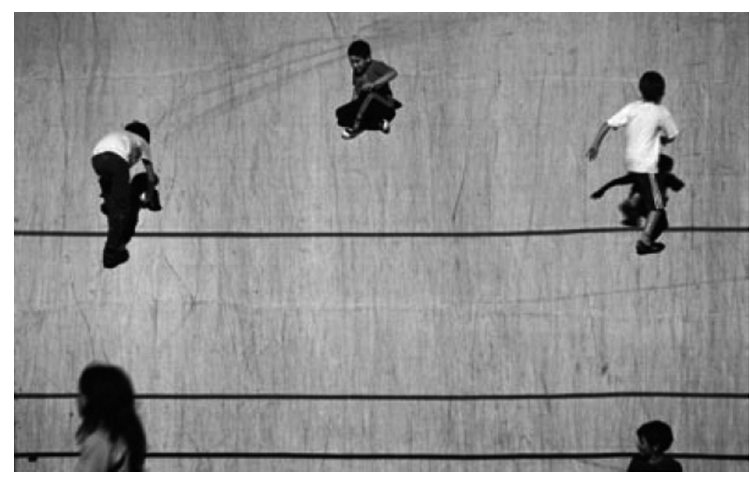

Fotografía de la colección Tonos cruzar, de diferentes años y lugares. Esta colección se caracteriza por integrar a personas que parecen no relacionarse en ese momento, pero que están a punto de encontrarse. Autor: Andrés Cribari.

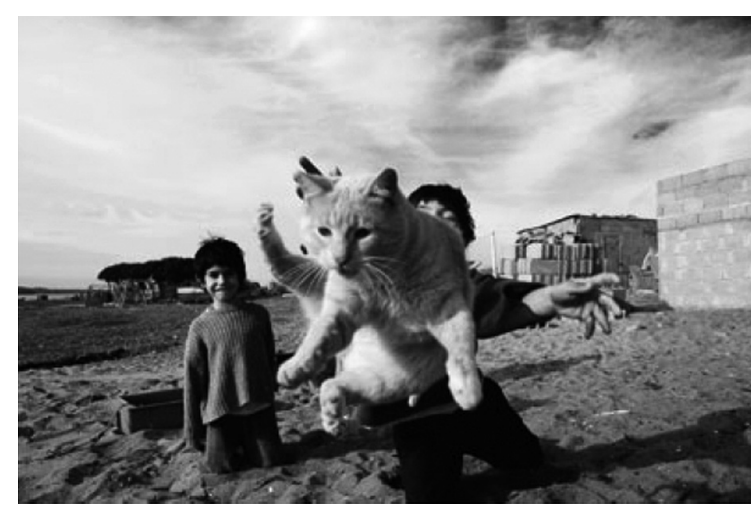

Fotografía de la colección Iguales a la par - Comunidad de niños de la Laguna de Rocha. Esta colección cuenta las condiciones extremas en que vive una comunidad de pescadores, a orillas de la desembocadura de la Laguna de Rocha. Autor: Santiago Barreiro. 


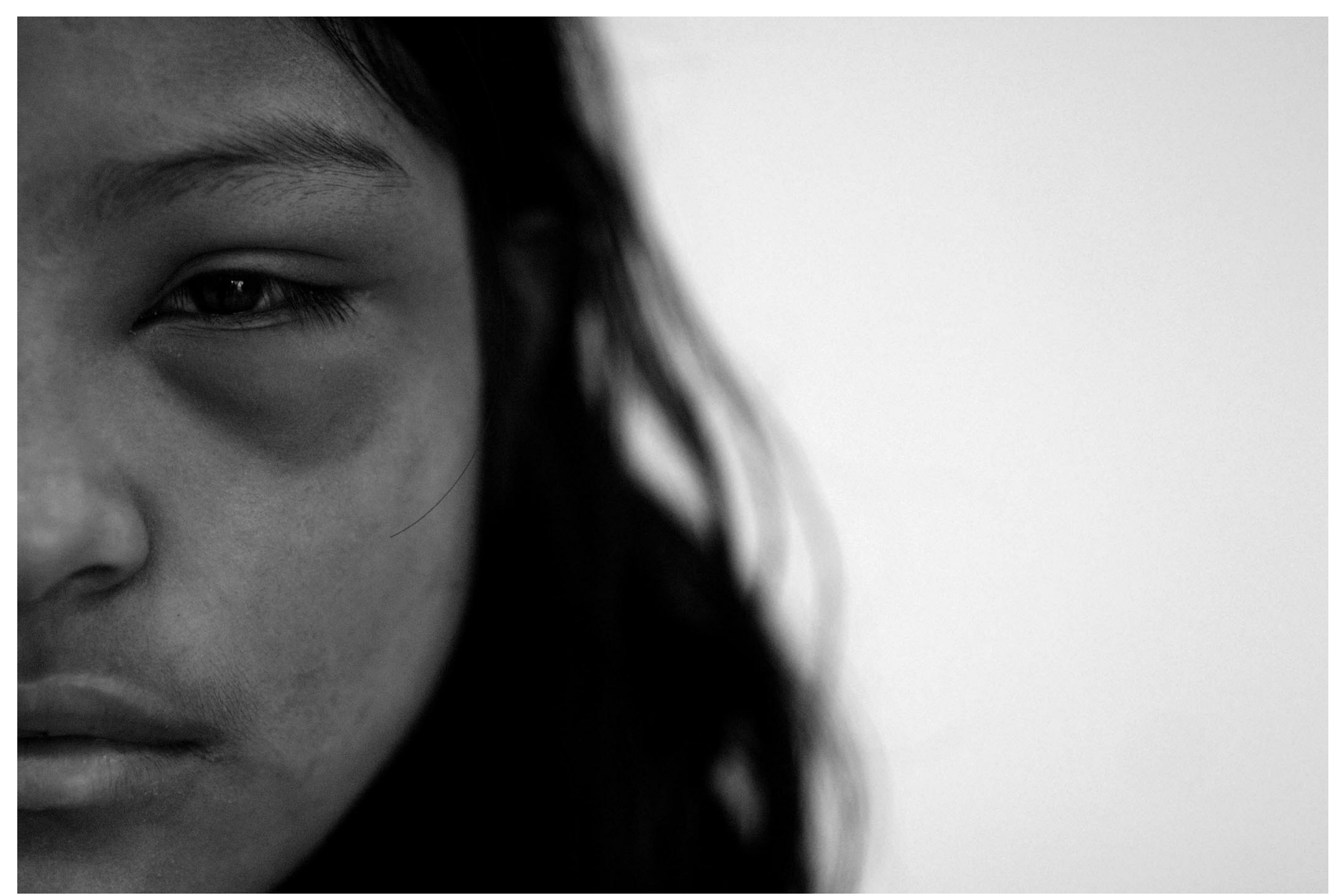

Guatemala, 2006. Yoselin Sarai Pérez Hidalgo, de 15 años, después de denunciar a su novio, de 27 años, en el Ministerio Público. Autor: Walter Astrada.

\section{Fotograma en la Universidad Católica}

Walter Astrada (Argentina, 1974) ha sido fotógrafo para medios de comunicación de diferentes países de América Latina y Europa. Ha trabajado para agencias internacionales de noticias, como Associated Press (AP) y France Press (AFP). En 2006 se radicó en España, para cubrir África del Este para la APF. Desde ese año, Astrada ha estado documentando el problema de la violencia contra las mujeres. La Universidad Católica del Uruguay expone este trabajo en el que Astrada presenta imágenes impactantes de la más extendida violación de los derechos humanos en el mundo, de acuerdo a investigaciones de la ONU y otras organizaciones humanistas.

La exposición Violencia contra las mujeres es un proyecto de documentación en desarrollo. La parte denominada Feminicidio en Guatemala aborda la problemática de las muertes violentas de mujeres, como una demostración de poder y dominio por parte de los hombres, las cuales han aumentado en los últimos años en Centroamérica y se caracterizan por una brutalidad y ensañamiento excepcionales. La otra parte de la exposición, denominada Violación, arma de guerra en el este de la República Democrática del Congo aborda la violencia sexual en aquel país, donde miles de mujeres son violadas con total impunidad por los actores involucrados en el conflicto, como civiles, milicias, grupos armados nacionales y extranjeros y miembros del ejército congolés. El sexo es utilizado como un arma de guerra para castigar o deshumanizar a las mujeres, o perseguir a la comunidad a la que pertenecen.

Fotos cedidas por Walter Astrada.

Más información: página de Walter Astrada, http://www.walterastrada.com 


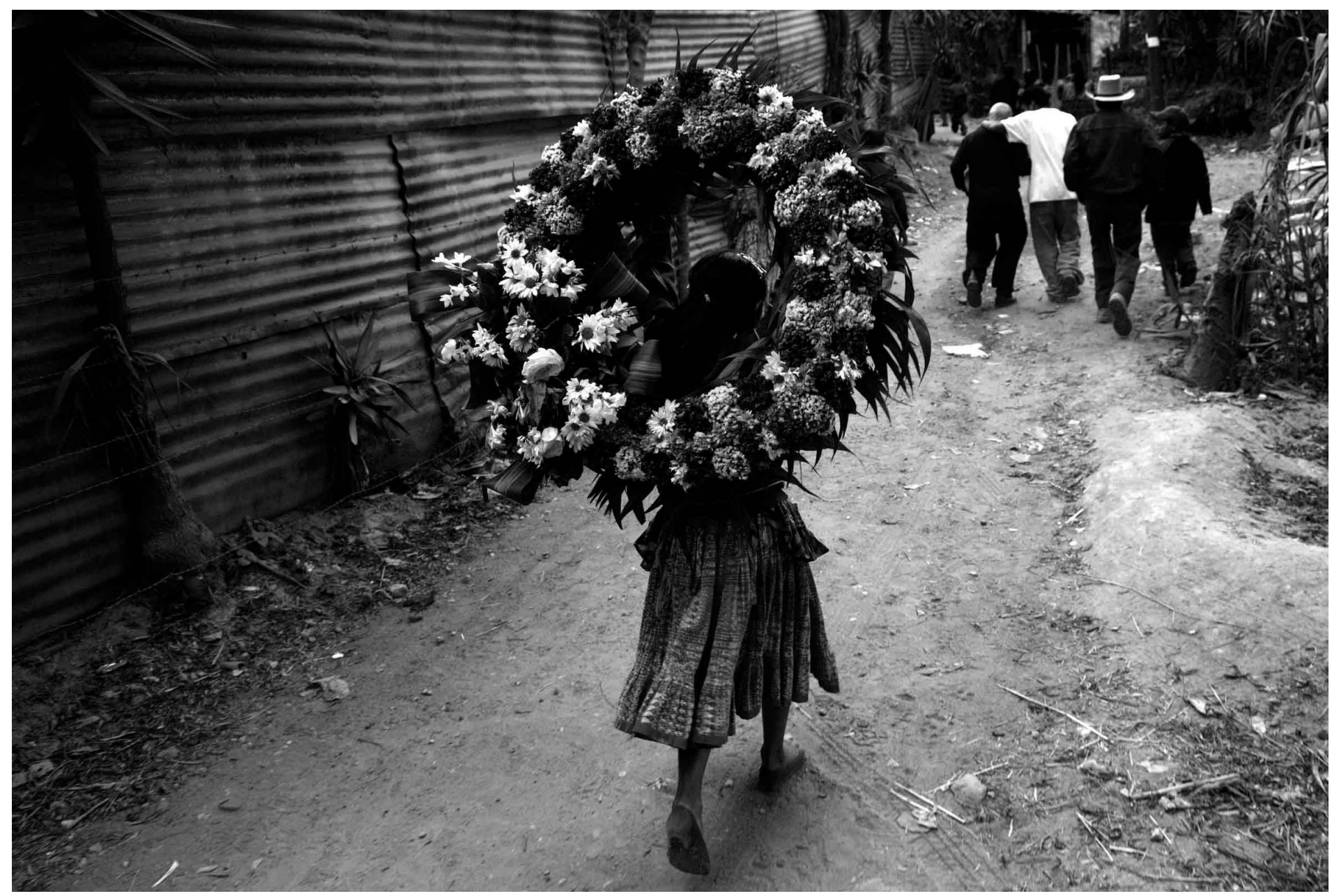

Guatemala, 2007. Dolientes de Rosa Vázquez Marroquín, de 69 años, quien fue encontrada en un precipicio en Nueva Chinautla. Autor: Walter Astrada.

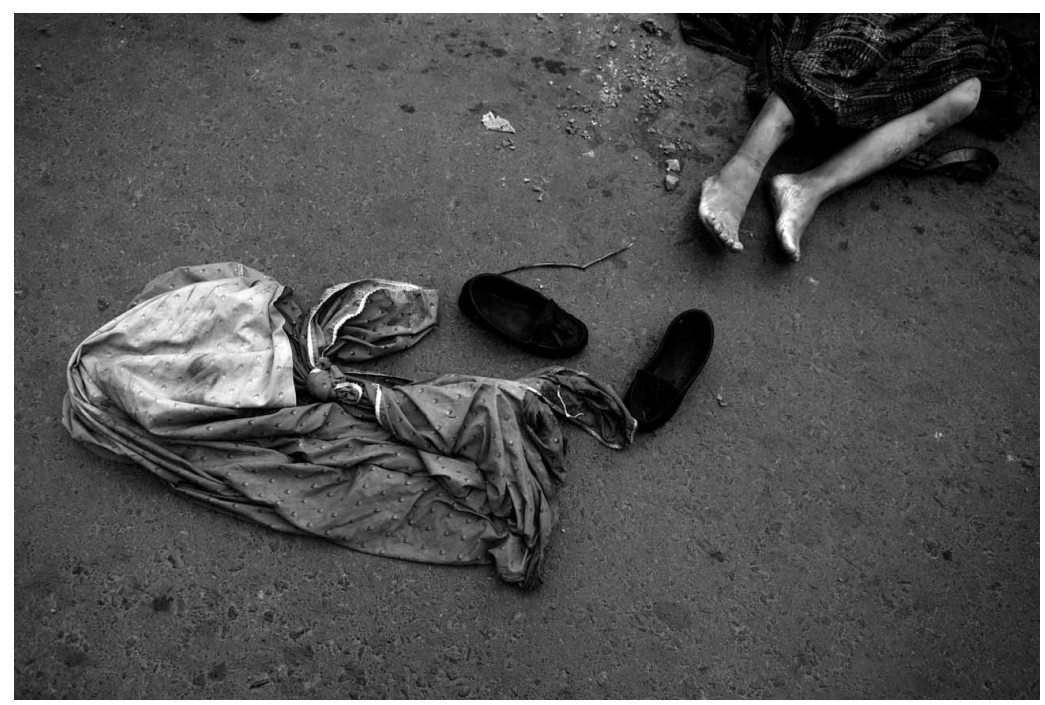

Guatemala, 2007. Una mujer no identificada, encontrada muerta junto a Rosa Vázquez Marroquín, en Nueva Chinautla. Autor: Walter Astrada. 


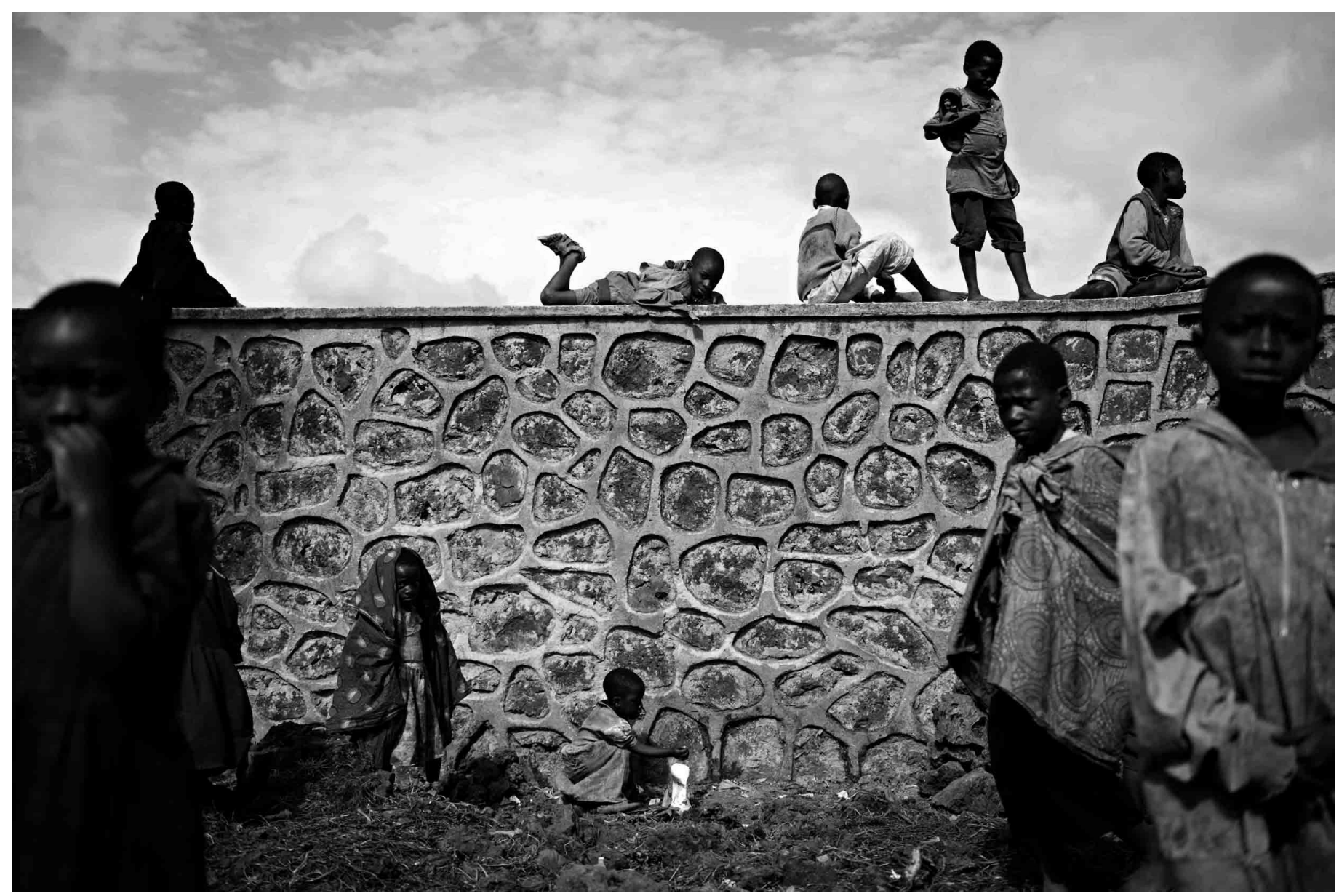

Congo, 2008. Un grupo de niños espera en el patio de la clínica de Mercy Corps por una distribución de galletas energéticas en el campo de desplazados de Kibati. Autor: Walter Astrada.

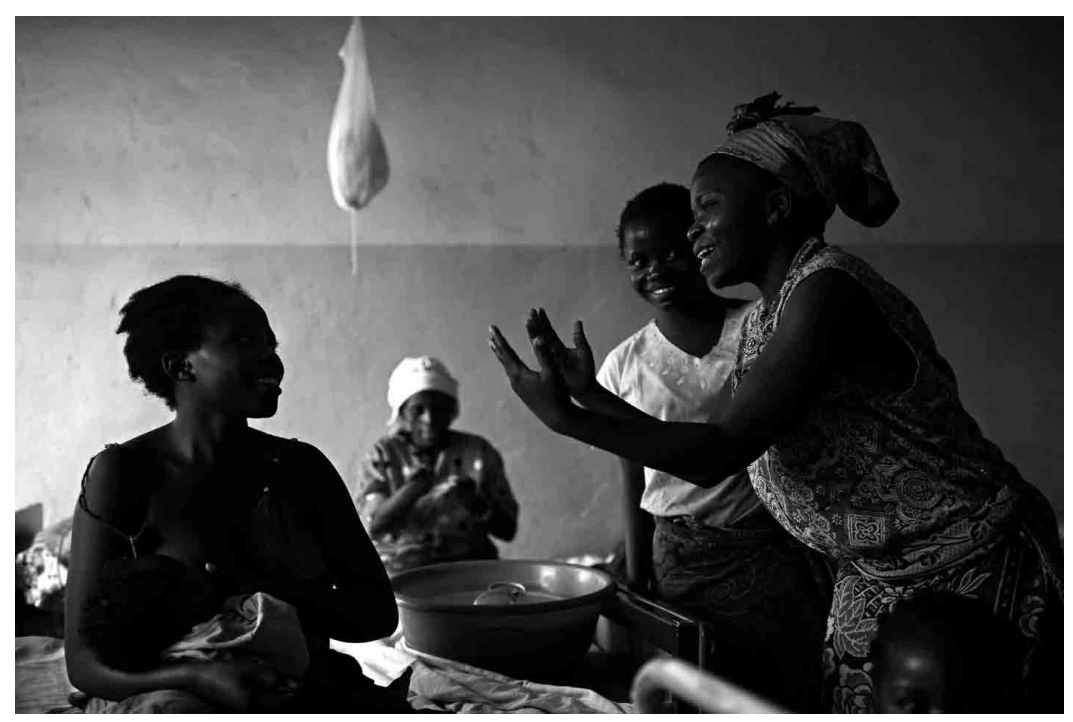

Congo, 2008. Una mujer cantando a otra, quien dio a luz a un bebé resultado de una violación. Autor: Walter Astrada. 